\begin{tabular}{|c|c|c|}
\hline $\begin{array}{l}\text { PUCRS } \\
\text { PUCR }\end{array}$ & $\begin{array}{l}\text { ESCOLA DE } \\
\text { HUMANIDADES }\end{array}$ & $\begin{array}{l}\text { Revista Digital do Programa de Pós-Graduação em Letras da PUCRS } \\
\text { Letrônica, Porto Alegre, v. 14, n. 2, p. 1-17, abr.-jun. } 2021 \\
\text { e-ISSN: } 1984-4301\end{array}$ \\
\hline (6) $h$ ttp: //dx & $\mathrm{rg} / 10.15448 / 1984-4301.2021 .2 .38792$ & \\
\hline
\end{tabular}

SEÇÃO: ARTIGOS

\title{
Teorias Neurocognitivas de Aprendizagem da Leitura e Métodos de Alfabetização
}

\author{
Neurocognitive Theories of Reading and Literacy Methods
}

\author{
Mariana Terra Teixeira ${ }^{1}$ \\ orcid.org/0000-0002-5115-1234 \\ mariana.teixeira@edu.pucrs.br
}

\section{Aline Fay de Azevedo' \\ orcid.org/0000-0002-7180-903X} aline.azevedo@pucrs.br

Recebido em: 8/5/2020 Aprovado em: 28/10/2020. Publicado em: 10/8/2021

\section{(c) (i)}

Artigo está licenciado sob forma de uma licença Creative Commons Atribuição 4.0 Internacional.
Resumo: No terceiro ano do ensino fundamental, transcorridos três anos escolares inteiros, $22 \%$ dos alunos conseguem ler somente palavras soltas (INEP/ ANA, 2016). As dificuldades com a leitura e a escrita estão associadas ao método de ensino e à ausência de práticas de letramento apropriadas. A maioria das crianças possuem dificuldades de aprendizagem que podem ser ultrapassadas com instrução adequada. A questão central discutida neste artigo é que, para a criança aprender a ler, é preciso lhe ensinar a ler. Portanto, o presente artigo teve como objetivos (1) discutir e trazer exemplos efetivos sobre como as teorias neurocognitivas de aprendizagem da leitura podem nos ajudar a pensar em um método de alfabetização e ensino da leitura mais eficaz, e (2) a criação de um panfleto informativo para professores de ensino fundamental anos iniciais, cujo foco é ilustrar e fazer sugestões práticas sobre alfabetização baseada em evidências científicas. A partir de evidências de estudos neurocognitivos que sublinham a importância do ensino do princípio alfabético e do desenvolvimento da consciência fonológica, elaboramos um panfleto com dicas e técnicas práticas para o ensino da leitura com base no método fônico, método que corresponde às evidências dos estudos neurocognitivos resenhados neste artigo.

Palavras-chave: Alfabetização. Métodos. Aprendizagem da leitura. Dificuldade de leitura. Neurobiologia da leitura.

Abstract: In the third year of elementary school, after three full school years, 22\% of students can read only single words in Brazil (INEP, 2016). Difficulties with reading and writing are associated with the teaching method and the absence of appropriate literacy practices. Most children that have learning difficulties can overcome it with proper instruction. The central issue discussed in this article is that for the children to learn to read, it is necessary to explicitly teach them to read. Therefore, this paper aim to (1) discuss and bring effective examples of how neuroscientific theories of reading can help us find the more effective method of literacy and teaching reading, and (2) the creation of an informative brochure for elementary school teachers, whose focus is to illustrate and make practical suggestions on scientific evidence-based literacy. Based on evidence from neuroscientific studies that underline the importance of teaching the alphabetical principle and the development of phonological awareness, we have prepared a pamphlet with practical tips and techniques for teaching reading based on the phonic method, a method that corresponds to the evidence from neuroscientific studies reviewed in this paper.

Keywords: Literacy. Methods. Reading learning. Reading difficulty. Neurobiology of reading.

\section{Introdução}

A educação básica brasileira ainda se caracteriza como um desafio para pesquisadores da área da educação e de áreas correlatas. Com programas governamentais intensificados no Brasil desde 2002, a universalização do ensino fundamental, em especial, a alfabetização da população, pratica- 
mente se concretizou em nosso pais. Segundo a última Pesquisa Nacional por Amostra de Domicilios (PNAD), realizada pelo Instituto Brasileiro de Geografia e Estatística (IBGE), divulgada em 2020, o índice de analfabetismo do Brasil é apenas de 6,6\% (IBGE, 2020). Esse é um índice baixo para o tamanho do nosso pais, embora informe que 11,3 milhões de pessoas ainda não sabem ler no Brasil. Os indices mais preocupantes, entretanto, são os de compreensão do que se lê. Em 2018, o índice de analfabetismo funcional chegou a 29\% (INSTITUTO PAULO MONTENEGRO, 2018). Isso quer dizer que quase um terço da população brasileira "mesmo sabendo ler e escrever algo simples, não tem as competências necessárias para satisfazer as demandas do seu dia a dia e viabilizar o seu desenvolvimento pessoal e profissional" (INSTITUTO PAULO MONTEIRO, 2018, p. 91).

A pergunta que reside nos dados e que queremos levantar aqui é como passamos da universalização do acesso ao ensino da leitura à alfabetização eficiente e à leitura fluente. Afinal, algo de errado está acontecendo, posto que os alunos têm acesso ao ensino da leitura, mas saem dele sem conseguir compreender um texto simples. Ao analisar cuidadosamente os dados referentes ao ensino fundamental, divulgados pela Secretaria de Educação Básica (Saeb), percebemos que as dificuldades de leitura e compreensão começam cedo. No terceiro ano do ensino fundamental, isto é, transcorridos três anos escolares inteiros, $22 \%$ dos alunos conseguem ler somente palavras soltas (INEP, 2016; 2018). O ensino é cumulativo e as dificuldades aumentam. Cinco anos depois, ao chegarem ao sétimo ano do ensino fundamental, $55 \%$ dos estudantes brasileiros estão abaixo do nivel 2 de leitura, considerado pela Organização para Cooperação e Desenvolvimento Econômico (OCDE) o nivel mínimo necessário para o exercício pleno da cidadania (INEP, 2018). Isso quer dizer que $55 \%$ dos estudantes brasileiros do sétimo ano, com 15 anos de idade, conseguem identificar somente informações explícitas em textos curtos e, em textos um pouco maiores, somente se a informação estiver no titulo ou na primeira linha. Com base nesses números, concluímos que o ensino eficiente da leitura ainda se constitui um desafio no Brasil.
As dificuldades com a leitura e a escrita estão associadas ao método de ensino e à ausência de práticas de letramento apropriadas. A maioria das crianças possuem dificuldades de aprendizagem que podem ser ultrapassadas com instrução adequada. Por outro lado, algumas crianças têm dificuldades persistentes que podem ser indicativas de um transtorno de aprendizagem. Transtornos de aprendizagem são dificuldades permanentes no aprendizado da leitura, da escrita e do cálculo. O transtorno de aprendizagem específico da leitura é percebido em crianças que, apesar da instrução formal, não conseguem aprender a ler. Estas crianças que dentro de um espectro de desempenho leitor encontram-se inesperadamente e persistentemente em percentis inferiores de indices desempenho, como a fluência, são diagnosticadas com a dislexia do desenvolvimento. $A$ dislexia é um transtorno de origem neurobiológica e que se apresenta como uma dificuldade severa no aprendizado da leitura (SHAYWITZ, 2006).

A linguagem humana é natural enquanto fala, já nascemos biologicamente programados para desenvolver a linguagem oral. Existe uma rede neural inata para o processamento da linguagem oral que é semelhante em diversas línguas (RUECKL et al., 2015). Já a escrita e a leitura são construções culturais que dependem de instrução para que sejam desenvolvidas. O código escrito é artificial, uma invenção cultural humana, criado por volta de 4 a 5 mil anos antes de Cristo. Sendo a escrita artificial, nós precisamos aprendê-la, nosso cérebro precisa adaptar-se a ela. Quando aprendemos a ler, nosso cérebro sofre um processo de adaptação de suas redes neuronais para conseguir codificar sons em letras, função que não exercia anteriormente ao aprendizado da leitura. A questão central de nosso artigo é que, para a criança aprender a ler, é preciso que antes the seja ensinado a ler. A questão da instrução da leitura é o que nos leva a pensar sobre os métodos de alfabetização existentes e sobre aqueles que são utilizados no Brasil. Algo nos leva aos 55\% de adolescentes de 15 anos que não compreendem o que leem (INEP, 2018) e à existência de $29 \%$ de analfabetos funcionais no Brasil (INSTITUTO PAULO MONTEIRO, 2018). 
Portanto, o presente artigo tem como objetivos (1) discutir e trazer exemplos efetivos sobre como as teorias neurocientíficas de aprendizagem da leitura podem nos ajudar a pensar em um método de alfabetização e ensino da leitura mais eficaz, e (2) a criação de um panfleto informativo para professores de ensino fundamental anos iniciais, cujo foco é ilustrar e fazer sugestões práticas sobre alfabetização baseada em evidências científicas.

Em sintese, quanto melhor entendermos como ocorre a aprendizagem da leitura pelas crianças, mais conseguiremos ajudar os estudantes com dificuldade de leitura e compreensão. A aprendizagem da leitura pode ser tema de pesquisa de várias áreas, da educação, da linguística, da psicologia escolar e da neurociência cognitiva. Aqui, por meio de um enfoque neurocognitivo, buscamos entender como ocorrem os processos envolvidos na aprendizagem da leitura e como entendê-los nos leva à seleção de um melhor método para alfabetização das crianças brasileiras, visto que os dados nos mostram que a situação é crítica. Para tanto, na seção 1, abaixo, apresentaremos processos cognitivos envolvidos no aprendizado da leitura e teorias cognitivas de aprendizagem da leitura; na seção 2, abordaremos o conflito entre dois métodos de alfabetização divergentes, métodos utilizados para alfabetizar crianças no Brasil; e na seção 3, trazemos evidências neurocognitivas sobre como o cérebro aprende a ler e também dicas e técnicas práticas baseadas nas neurociências para melhorar a leitura e o aprendizado da leitura dos alunos em anos iniciais do ensino fundamental. Por fim, tecemos nossas considerações finais sobre o aprendizado da leitura do ponto de vista teórico neurocognitivo.

\section{Compreensão do princípio alfabético e a consciência fonológica: a chave para a aprendizagem da leitura e a independência do futuro leitor}

Como vimos na introdução, aprender a ler é bastante diferente de aprender a falar. Todas as línguas têm uma modalidade falada, mas nem todas possuem uma versão escrita (LENT, 2010). Diferente de outras capacidades, inatas ao ser humano, tais como falar e andar, a leitura precisa ser ensinada. Segundo Snowling e Hulme (2013), ao ingressar no ensino fundamental, geralmente, aos seis anos de idade, a criança já demonstra competência oral em sua lingua materna, e a competência da leitura se desenvolverá a partir dessa base.

Na idade pré-escolar, o foco da atenção das crianças durante a fala é, geralmente, entender o significado daquilo que está sendo dito. Contudo, é preciso mostrar às crianças que a linguagem possui também outras facetas, tais como a sua forma e a sua estrutura. Nem sempre esse processo de redirecionamento do foco das crianças é simples e fácil. Primeiramente as crianças devem desenvolver o conhecimento consciente e reflexivo das partes das palavras ou de como elas se organizam na linguagem oral (ADAMS et al., 2012) para então, em um segundo momento, poderem passar ao aprendizado do sistema representacional dessa fala.

Nas linguas cujo sistema de escrita é alfabético, como é o caso da língua portuguesa, a capacidade de independência do leitor resulta do domínio de três condições: compreensão do princípio alfabético, capacidade de decodificação e constituição do léxico-mental ortográfico (DEHAENE, 2012). Para compreender o princípio alfabético, é preciso ensinar ao individuo que as palavras são formadas por letras, também denominadas grafemas, as quais representam os sons da fala, denominados fonemas (menor unidade de som da língua oral). O individuo pré- leitor não descobre/compreende o princípio alfabético somente por meio de exposição ao material escrito, ele precisa ser guiado e ajudado, com exercícios apropriados, a tomar consciência dos fonemas (MORAIS, 2014).

Com o intuito de decodificar qualquer palavra na sua lingua, o leitor aprendiz deve assimilar as valências entre os grafemas e os fonemas e adquirir progressivamente o conhecimento do código ortográfico da sua língua, pois cada língua possui um código ortográfico particular, formado historicamente. Depois de compreender o princípio alfabético, o indivíduo deve progredir no conhecimento das valências, por meio do ensino explícito 
e da prática de leitura, tornando-se assim capaz de associar os grafemas que encontra nas palavras aos fonemas correspondentes. Esse processo vai sendo executado com mais rapidez e precisão ao longo do tempo. Segundo Morais (2014), a decodificação das palavras escritas compreende três processos ordenados no tempo: a decomposição da palavra escrita em uma sequência de grafemas, o emparelhamento destes com os fonemas correspondentes e, por fim, a integração ou fusão dos fonemas sucessivos de cada sílaba de maneira a obter a pronúncia da palavra.

Para a total constituição do léxico mental ortográfico, o individuo deve ter a forma escrita das palavras memorizada, o que libera recursos linguísticos e cognitivos para as operações de análise sintática e de integração semântica que fazem parte do processo de compreensão dos textos. Porém, para adquirir o léxico mental ortográfico, é preciso passar pela etapa da decodificação (MORAIS, 2014).

Como visto, a tarefa principal do indivíduo no desenvolvimento inicial da leitura em um sistema de escrita alfabético é entender e dominar o princípio alfabético, segundo o qual a fala pode ser segmentada em fonemas. Estes, por sua vez, são representados, na forma escrita, por grafemas, que utilizam símbolos do código ortográfico da língua na qual o indivíduo está sendo alfabetizado (FLETCHER et al., 2009; MORAIS, 2014).

Segundo Morais (1996), a chave da linguagem escrita encontra-se na relação do principio alfabético com a linguagem falada. Essa chave seria a consciência fonológica (CF). De acordo com Azevedo (2016), a CF pode ser definida como a capacidade de reflexão e manipulação consciente dos sons da fala e o conhecimento acerca da estrutura sonora da linguagem que se desenvolve mediante contato com a linguagem oral de sua comunidade. A CF envolve a manipulação oral e auditiva dos sons da fala (CHARD; DICKSON, 1999), independente do seu significado. Para Cielo (1998), é a habilidade em analisar, explicitamente, a fala em seus componentes fonológicos. Outras denominações para o termo CF são "sensibilidade fonológica" ou "habilidades metafonológicas".
Quando o segmento envolvido nas tarefas de CF é o fonema, denomina-se consciência fonêmica.

Segundo Morais (1996), há três niveis de consciência fonológica: o silábico, o intrassilábico e o fonêmico. O nível silábico é um conhecimento que adquirimos cedo e que pode desenvolver-se antes da criança aprender a ler e escrever. As crianças já começam a ter consciência de que existe uma relação entre fala e escrita, entre os aspectos gráficos e sonoros das palavras. Elas tentam dar valor sonoro a letras e sinais para representar as palavras, e deduzem que, para cada sílaba pronunciada, o indivíduo escreve uma letra (uma letra para cada sílaba), ou para cada palavra em uma frase dita. No nivel intrassilábico, as palavras podem ser divididas em unidades maiores que um fonema individual, mas menores que uma sílaba. Na teoria da sílaba, é denominado de aliteração e rima. Aliteração são palavras que apresentam o mesmo onset (início/começo), ou seja, uma série de duas ou mais palavras que começam pelo mesmo som consonantal inicial, como, por exemplo, "brinco" e "bruxa" (SHAYWITZ, 2006). A rima da palavra seria a igualdade entre os sons, desde a vogal ou ditongo tônico até o último som, como, por exemplo, "martelo" e "castelo". Já a rima da sílaba seria formada por palavras que terminam com o mesmo som, por exemplo, "balão" e "coração", "chapéu" e "anel". Por fim, temos o nível fonêmico que compreende a capacidade de dividir as palavras em fonemas, unidades minimas sonoras capazes de distinguir significado.

A consciência fonológica depende do processamento fonológico do indivíduo. O processamento fonológico pode ser visto como a capacidade de utilizar informações fonológicas para processar a linguagem oral e escrita (NASCIMENTO; KNOBEL, 2009). Pode ser considerado uma operação mental em que o individuo faz uso oral da estrutura fonológica de uma determinada língua para aprender a decodificá-la no plano escrito (NAVAS; SANTOS, 2002).

O processamento fonológico envolve habilidades como: 
a) discriminação auditiva: perceber se "vaca" é diferente de "faca". Detectar, identificar e reconhecer padrões de frequência, intensidade e duração, ou seja, habilidade auditiva;

b) memória fonológica: habilidade para processar, manter e recuperar a informação verbal;

c) produção fonológica: articulação das palavras.

Segundo Pinheiro (2000), as crianças demonstram algumas habilidades em consciência fonológica desde cedo, como vimos acima, detecção de silabas, aliteração e rimas. Já outras habilidades, tais como o apagamento, contagem e manipulação de fonemas, emergem mais tarde e podem sofrer influência da alfabetização. A autora afirma que a CF é um componente crítico para a aquisição da leitura. Nesse sentido, há evidências significativas de que a aprendizagem da leitura depende da consciência fonológica (NATIONAL READING PANEL, 2000).

Goswani (2002) afirma que quanto melhor o desempenho das crianças na leitura, maior a sensibilidade que elas apresentam quanto aos constituintes sonoros das palavras. A existência de uma relação de reciprocidade entre a CF e a aquisição de leitura alcança um amplo consenso atualmente e, segundo essa concepção, essas habilidades estão ligadas para facilitar uma à outra, desenvolvendo-se através de uma influência reciproca (MORAIS, 1996; MOOJEN, 2009).

No Brasil, Salles (2005) apresenta um estudo em que foram analisadas 76 crianças, em início de segunda e terceira séries do ensino fundamental (atualmente chamadas de anos, terceiros e quartos anos, respectivamente, e não mais séries), quanto às habilidades de precisão na leitura de palavras isoladas, compreensão de leitura, tempo de leitura textual e CF. Os resultados apontaram a CF como o melhor preditor da variância em precisão na leitura de palavras isoladas e em compreensão de leitura. Essa pesquisa de Salles (2005) corrobora as afirmações de Stanovich, Cunningham, Cramer (1984) e Pinheiro (2000) de que o grau de desenvolvimento de CF é um dos melhores preditores da facilidade de aquisição da leitura, tendo um papel causal e representando uma condição necessária, mas não suficiente nesse processo.
Com base no que foi apresentado sobre o princípio alfabético e a consciência fonológica, passamos à seção sobre a aprendizagem da leitura per se e as teorias neurocognitivas.

\subsection{Teorias neurocognitivas sobre como ocorre o processo de aprendizagem da leitura pelo cérebro humano}

As crianças adquirem a língua falada espontaneamente, por meio de um processo que não exige instrução, somente exposição. Por outro lado, a aprendizagem da leitura não ocorre breve e espontaneamente (MORAIS, 2013). A leitura implica na aprendizagem de um conjunto complexo de operações de representações gráficas que representam operações fonológicas e semânticas, processo que cria uma interface visual para a língua. Segundo Dehaene (2012), essa interface possui invariância espacial e visual que possibilita o reconhecimento das palavras em qualquer posição e em qualquer fonte de escrita. Aárea cerebral que se especializa nessa interface visual especifica da leitura foi chamada de "área da forma visual das palavras". Esta é uma área entre os lóbulos occipital e temporal no cérebro, localizada entre duas áreas que antes eram áreas de identificação de faces e objetos. Essas duas áreas reciclaram o seu papel no cérebro e "emprestam" as suas habilidades para a função de identificação de letras.

Como vimos na seção 1, acima, o modo mais eficaz para a aprendizagem da leitura é a compreensão do principio alfabético (MORAIS; KOLINSKY, 2015). A compreensão do princípio alfabético requer a tomada de consciência dos fonemas, a sua associação às letras e aos grafemas, e o desenvolvimento de habilidades para operar mentalmente com representações fonêmicas (fonemas) e, de forma mais geral, para operar com representações fonológicas (sílabas, rimas, aliterações, apagamento e substituição de silabas nas palavras). Tendo compreendido o princípio alfabético, a criança desenvolve a habilidade de decodificação. Uma habilidade de decodificação eficiente alicerça uma leitura autônoma e fluente que, por sua vez, alicerça o desenvolvimento da compreensão leitora. Abaixo, veremos algumas teorias cognitivas sobre a aprendizagem da leitura 
em sistemas alfabéticos, que, como dissemos, é o caso do português brasileiro.

O processo de aprendizagem da leitura é complexo porque requer mudanças no cérebro do aprendiz. A teoria mais influente na ciência da leitura é a de Frith (1985). Segundo essa teoria, a aprendizagem da leitura acontece em três fases ${ }^{2}$ principais. Na fase pictórica/logográfica, a criança identifica imagens, devido a traços gráficos salientes, cores e formas, que agem como pistas para ativar a memória. A ordem das letras é ignorada pela criança, pois ela memorizou a forma visual, e os traços fonológicos são secundários (FRITH, 1985). É como o reconhecimento de um objeto visual. Exemplos bastante citados na literatura são os símbolos da Coca-Cola ou da PEPSI, marcas conhecidas de refrigerantes. Mesmo invertendo as letras no interior dos símbolos, como em Caco-Calo ou PSEPI, se mantidos os seus traços gráficos mais característicos, as crianças os reconheceriam ainda assim.

Na fase alfabética, a criança consolida o conhecimento da correspondência grafema-fonema, ou seja, consolida a decodificação das letras individualmente. A ordem das letras e os fatores fonológicos desempenham um papel maior, porque não há mais o tratamento global da palavra. Seria a fase da constituição do que hoje dizemos ser a rota fonológica, segundo o Modelo de Dupla-Rota de Leitura (ELLIS, 1995; HILLIS; CARAMAZZA, 1992), como veremos mais adiante, na seção 3 deste artigo, sobre evidências neurocognitivas. Por fim, na fase ortográfica, os leitores operam com unidades maiores, e nem sempre é necessária a decodificação no caso da ortografia de palavras já memorizadas. As unidades ortográficas passam a ser os morfemas ou sequências de letras. Seria a fase de constituição da rota lexical do Modelo de Dupla-Rota de Leitura. Nessa fase, a leitura já está automatizada, a consciência fonêmica já está desenvolvida, e a criança lê com fluência. Essas fases não são estanques, porque continuamente a criança transita por elas devido à aquisição de novas palavras. Do mesmo modo, veremos que o uso das rotas de leitura também não é estanque, já que ambas as rotas são utilizadas por leitores fluentes.

Quando as crianças se tornam leitoras fluentes, mais recursos cognitivos ficam disponiveis para que a compreensão da leitura ocorra. Ler com fluência é um importante passo para compreender o que se lê. Segundo o Instituto Alfa e Beto, fluência é:

a facilidade para reproduzir oralmente uma sequência de palavras escritas presentes em uma lista ou em um texto organizado. A facilidade é definida pela precisão, rapidez e automaticidade no reconhecimento das palavras. ${ }^{3}$

Quando o leitor reconhece automaticamente as palavras, consegue ler de maneira mais rápida, e, assim, menos recursos são utilizados para acessar o significado das palavras. Quanto menos recursos são utilizados para o processamento das palavras, mais facilmente o leitor consegue compreender uma sentença ou um texto que está repleto delas.

A teoria de leitura mais atual que segue a linha de fases do desenvolvimento da leitura de Frith (1995) é a de Ehri (2005; 2014). Ehri (2005; 2014) distingue quatro maneiras de ler palavras, e essas quatro maneiras são utilizadas pelas crianças diferentemente nas quatro fases do desenvolvimento da leitura e da escrita propostas pela autora. Nos dois quadros abaixo, temos as maneiras de ler as palavras e as fases da leitura propostas por Ehri (2005; 2014).

\footnotetext{
2 As teorias sobre o desenvolvimento da leitura descritas aqui utilizam o termo fases e não estágios de desenvolvimento da leitura. Segundo Ehri (2005), uma teoria de estágios é mais rigorosa, pois os conhecimentos de um estágio são pré-requisitos para o desenvolvimento do próximo estágio, o que não acontece necessariamente em uma teoria de fases do desenvolvimento. Por exemplo, segundo a autora, como veremos na sua teoria de desenvolvimento da leitura e da escrita (EHRI, 2005: 2014), a fase pré-alfabética de leitura não contribui para as fases posteriores de desenvolvimento da leitura. Uma teoria de estágios também é estanque, uma teoria de fases não, porque "diferentemente dos estágios qualitativamente distintos, as crianças podem usar conexões de mais de uma fase para aprender as palavras" (EHRI, 2005, p. 176).

3 Esta é a definição do Programa Alfa e Beto de Fluência de Leitura, programa pago. Disponível em: https://alfaebetosolucoes.org.br/ ensino-publico/programa-alfa-e-beto/. Acesso em: 7 jan. 2020.
} 
Quadro 1 - Maneiras de ler palavras

\begin{tabular}{|c|c|}
\hline \multicolumn{2}{|r|}{ Maneiras de Ler Palavras (EHRI, 2005; 2014) } \\
\hline MANEIRAS & DEFINIÇÃO \\
\hline Predição & $\begin{array}{l}\text { É a maneira mais simples de ler palavras. Tenta-se "adivinhar" a palavra escrita por meio } \\
\text { do contexto (por exemplo, cores, formas imagens) ou pela presença de alguns elemen- } \\
\text { tos conhecidos, como as letras iniciais. É utilizando essa estratégia que crianças muito } \\
\text { pequenas são capazes de "ler" nomes de produtos, marcas ou empresas em rótulos, } \\
\text { outdoors e placas. Leitores proficientes também podem usar a predição para descobrir } \\
\text { uma palavra incompleta: por exemplo, na frase "no hospital há muitos médicos e en...", o } \\
\text { contexto pode levar à suposição de que se trata de "enfermeiros" ou de "enfermos". }\end{array}$ \\
\hline Analogia & $\begin{array}{l}\text { É uma maneira um pouco mais precisa de ler palavras. Envolve o reconhecimento de } \\
\text { palavras por meio da associação com partes (rimas, por exemplo) de outras palavras } \\
\text { familiares. A criança que aprende a ler "gato" pode, por analogia, ler as palavras "rato", } \\
\text { "mato" e "pato". }\end{array}$ \\
\hline Decodificação & $\begin{array}{l}\text { É a maneira mais precisa de ler palavras e leva à automatização. É também a melhor es- } \\
\text { tratégia para ler palavras novas e permite a leitura autônoma de palavras desconhecidas. } \\
\text { Envolve o conhecimento das relações grafema-fonema para identificar o fonema corres- } \\
\text { pondente a cada grafema, aglutinando-os em pronúncias que formam palavras reconhe- } \\
\text { civeis. Contudo, quando a correspondência entre grafemas e fonemas em uma palavra } \\
\text { não é biunívoca, o leitor iniciante poderá ter dificuldade para extrair a pronúncia correta. }\end{array}$ \\
\hline $\begin{array}{l}\text { Reconhecimento } \\
\text { automático }\end{array}$ & $\begin{array}{l}\text { Depois que uma palavra é lida várias vezes, armazena-se na memória e passa a ser } \\
\text { reconhecida imediatamente, sem a necessidade de estratégias intermediárias como a } \\
\text { predição, a analogia e a decodificação. É a maneira mais eficiente e menos custosa para } \\
\text { a memória, permitindo que o leitor leia com rapidez e prosódia, faça inferências e com- } \\
\text { preenda frases e textos. }\end{array}$ \\
\hline
\end{tabular}

Fonte: Ehri (2005, apud MEC, 2019, p. 87-88)..

Quadro 2 - As fases do desenvolvimento da leitura e da escrita

\begin{tabular}{|l|l|}
\hline \multicolumn{1}{|c|}{ As Fases do Desenvolvimento da Leitura e da Escrita (EHRI 2005, 2014) } \\
\hline FASES & \multicolumn{1}{c|}{ DEFINIçÃo } \\
\hline Pré-alfabética & $\begin{array}{l}\text { A pessoa emprega predominantemente a estratégia de predição, usando de início pistas } \\
\text { visuais, sem recorrer às relações entre letras e sons; lê palavras familiares por reconheci- } \\
\text { mento de cores e formas salientes em um rótulo, mas é incapaz de identificar diferenças } \\
\text { nas letras; pode ainda conseguir escrever algumas palavras de memória. }\end{array}$ \\
\hline $\begin{array}{l}\text { Alfabética } \\
\text { parcial }\end{array}$ & $\begin{array}{l}\text { A pessoa faz analogias, utilizando pistas fonológicas; depois de aprender os sons das le- } \\
\text { tras, ela começa a utilizá-los para ler e escrever palavras. }\end{array}$ \\
\hline $\begin{array}{l}\text { Alfabética } \\
\text { completa }\end{array}$ & $\begin{array}{l}\text { Depois de conhecer todas as relações entre grafemas e fonemas e adquirir as habilidades } \\
\text { de decodificação e codificação, a pessoa passa a ler e a escrever palavras com autonomia. }\end{array}$ \\
\hline $\begin{array}{l}\text { Alfabética } \\
\text { consolidada }\end{array}$ & $\begin{array}{l}\text { Nesta fase de consolidação continua, ocorre o processamento de unidades cada vez maio- } \\
\text { res, como silabas e morfemas, o que permite à pessoa ler com mais velocidade, precisão e } \\
\text { fluência, e escrever com correção ortográfica. }\end{array}$ \\
\hline
\end{tabular}

Fonte: Ehri (2014, apud MEC,, 2019, p. 90-91). 
O que faz uma criança passar de uma fase para a outra, segunda a autora, é o conhecimento mais avançado do princípio alfabético. Ao final da aprendizagem da leitura, o leitor eficiente é aquele que identifica palavras com precisão, fluência e velocidade, dentro e fora dos textos (EHRI, 2005; 2014). A Teoria do Desenvolvimento da Leitura e da Escrita de Ehri $(2005$; 2014) é bastante relacionada com a teoria de Frith (1985). Ehri (2005; 2014), no entanto, como se pode ver nos quadros 1 e 2, inclui a escrita em sua descrição. A autora traz ainda, de maneira mais precisa, os processos cognitivos envolvidos na leitura que levam à automatização e, consequentemente, à leitura fluente. Como se pode ver na seção 3 deste artigo, sobre evidências da neurobiologia da leitura, quando a automatização acontece, palavras frequentes e já conhecidas do leitor utilizam uma rota neural mais "expressa" de leitura, a rota lexical, que, simplificadamente, podemos dizer que vai do reconhecimento das letras ao significado de maneira direta. Essa automatização só acontece depois que a decodificação está estabilizada e as relações grafema-fonema já estão consolidadas na memória dos leitores.

Ehri (2005; 2014) evoca nas suas diferentes maneiras de ler uma palavra que, ao lermos uma palavra desconhecida, utilizamos um processo e, ao lermos uma palavra, por exemplo, irregular, na qual a correspondência grafema-fonema não é biunivoca, utilizamos outro processo. A maneira de ler palavras desconhecidas é por meio da decodificação que, segundo a autora, "envolve o conhecimento das relações grafema-fonema para identificar o fonema correspondente a cada grafema, aglutinando-os em pronúncias que formam palavras reconheciveis" (MEC, 2019, p. 27). A maneira mais precisa de ler palavras irregulares é por meio do reconhecimento automático, uma vez que a pronúncia dessas palavras precisa ser memorizada, o reconhecimento da palavra pela sua forma faz com que o leitor a leia corretamente.

As teorias de aprendizagem da leitura e da escrita são a base para a constituição de métodos de ensino. Diferentes teorias geraram conflitos entre diferentes métodos de alfabetização. No Brasil, não foi diferente. Na seção abaixo, veremos o caso do nosso pais em específico.

\section{Métodos de alfabetização no Brasil}

Se um individuo estiver motivado e bem instruído, o processo de alfabetização em português é relativamente rápido em relação a outras linguas consideradas mais opacas. O desenvolvimento da capacidade de leitura é estimulado e se concretiza após a entrada da criança no ensino formal, que se dá, no Brasil, geralmente a partir dos seis anos de idade. Morais (2013) afirma que a grande maioria das crianças já possui todas as condições necessárias para serem alfabetizadas aos seis anos de idade. Contudo, em 2013, foi implementado, no país, o Pacto Nacional pela Alfabetização na Idade Certa (PNAIC), no qual foi estabelecido pelo Ministério da Educação (MEC) uma idade máxima (8 anos de idade $/ 3^{\circ}$ ano do ensino fundamental) para a alfabetização dos alunos da rede pública de ensino. Essa idade máxima é comumente chamada de "idade certa". Nesse contexto, os professores são orientados a não se alarmarem ao constatar que um de seus alunos não consiga ler adequadamente, mesmo este já tendo cursado o ensino formal por um ou dois anos. Somente seria considerado um problema se o referido aluno não alcançasse o nivel adequado de leitura depois de três anos de ensino formal. Novamente, o paradigma esperar para ver, ou "wait to fail" (REYNOLDS; SHAYWITZ, 2009).

Para Morais (2013), não há base cientíica para determinar uma idade certa para aprender a ler, pois há casos específicos de crianças que começam a aprender a decodificar aos três anos, por exemplo, e muitas outras poderiam fazê-lo desde os quatro, mas isso não seria necessariamente uma razão para estipularmos essa idade como a "idade certa". Conforme o autor, dentro dos limites impostos pelo desenvolvimento cognitivo da criança, essa fixação de idade teria como base critérios políticos e não cognitivos. Pode haver certa variedade na idade de início do processo, visto que algumas crianças são estimuladas pela familia desde pequenas. Entretanto, iniciado o processo, em uma língua de sistema alfabético semitransparente como o português brasileiro, 
as crianças deveriam levar de seis meses a um ano para estarem alfabetizadas (DEHAENE, 2012), levando em conta que elas têm instruções do ensino regular todos os dias da semana na escola. Assim, a questão principal é não esperar para ver, tendo-se iniciado o processo de alfabetização das crianças, seja aos 5, seja aos 6 anos de idade, elas têm de estar decodificando plenamente palavras e frases 1 ano após o início da instrução.

Já em agosto de 2019, em certa medida em oposição ao pacto de 2013, o MEC institui a Conferência Nacional de Alfabetização Baseada em Evidências (Conabe) e um painel de especialistas em alfabetização. Os objetivos específicos da Conabe 2019 foram apresentar e debater o estado da arte das pesquisas sobre alfabetização, literacia e numeracia; possibilitar a criação de um Relatório Nacional de Alfabetização Baseada em Evidências (Renabe), que exponha o estado da arte das pesquisas sobre alfabetização, literacia e numeracia; promover a divulgação do conhecimento científico mais atualizado sobre alfabetização, literacia e numeracia; propor recomendações para a melhoria da qualidade do ensino e da aprendizagem da literacia e da numeracia; e propor estratégias para seu cumprimento.

Como podemos ver, infelizmente, esse embate se estende até os dias atuais. Contudo, o debate da alfabetização no Brasil pode ser resumido, de uma maneira geral, em um conflito entre o método fônico e o construtivismo, o que replica o enfretamento que ocorre também em outros paises.

A teoria da Psicogênese da Lingua Escrita é baseada na teoria mais geral da psicologia do desenvolvimento natural da criança de Piaget (1974). Segundo Ferreiro e Teberosky (1986, p. 20), o método fônico era, na época - anos 80 , "um modelo mecanicista que, por não favorecer a compreensão do que se lê, seria um instrumento de dominação social, a expressão escolar do domínio das elites sobre as classes populares". No Brasil, as ideias e o método que representariam um novo jeito de alfabetizar e entender o aprendizado da leitura e da escrita em oposição a esse modelo fônico mecanicista ficou conhecido como construtivismo, por sua base ser a teoria construtivista de Piaget (1974). A teoria da aprendizagem de Piaget (1974), no entanto, não se estende à leitura e à escrita, tendo ficado esta extensão a cargo de Ferreiro e Teberosky (1986). Essas novas ideias referentes ao novo método de aprendizagem da leitura viriam a ser conhecidas como "whole language" nos Estados Unidos, representado pelo construtivismo americano de Goodman e seu artigo "Psycholinguistic Guessing Game" (GOODMAN, 1967).

O método global de alfabetização (whole language), desde antes do surgimento da força do construtivismo no Brasil, já constituía uma oposição ao método sintético tradicional (método fônico) no Brasil. O método global era também denominado de método analítico, método de palavração, ou método de sentenciação, e postulava que as crianças aprendem a partir da percepção do todo (SCLIAR-CABRAL, 2013). Dessa forma, a criança primeiro aprenderia a palavra como um todo, em contexto, e, depois, aprenderia a decompor as palavras em suas unidades menores. Resumidamente, segundo Scliar-Cabral (2013), o método global entendia que a linguagem funcionava como um todo, que a criança primeiro perceberia o todo para depois perceber as partes, que dar prioridade à compreensão era fundamental e que o leitor utilizava estratégias globais de reconhecimento. Esse método baseava-se em uma concepção holística da aprendizagem da leitura, em oposição ao método fônico e ao ensino "mecânico" dos sons das letras, dos fonemas e da descriminação das relações grafema-fonema, para o método global "aprender a ler e escrever é aprender a construir sentido para e por meio dos textos escritos, usando experiências e conhecimentos prévios" (SOARES, 2004, p. 12).

Segundo Magda Soares (2004), no método global, o sistema grafofônico das relações grafema-fonema não era ensinado às crianças, porque a aprendizagem dessas relações aconteceria de forma natural, quando as crianças entrassem em contato com a língua escrita. Aqui reside o grande problema do método global, pois aprender a ler não é natural e a criança precisa de instrução explícita para que isso ocorra. Dessa forma, veremos, na seção abaixo, que evidências neurobiológicas do aprendizado da leitura trazem a importância do 
método fônico, da instrução explícita dos principios alfabéticos e das relações entre letra e som, não só para o processo de decodificação, mas também para a automatização da leitura e uma leitura fluente. Nem a neurociência da leitura nem o método fônico preconizam que o ensino da leitura e da escrita se deve restringir às relações grafofonêmicas e a exercícios mecânicos de repetição, crítica frequente do método global ao método fônico. No entanto, este é, segundo os estudos neurocognitivos, um princípio básico da aprendizagem não natural da leitura, e a criança deve ser instruída do funcionamento do sistema grafofonêmico da língua no início do processo de alfabetização.

Scliar-Cabral (2013), em seu artigo, traz um exemplo retirado de uma das cartilhas que utilizavam o método global no Brasil, "O livro de Lili". O livro de Lili traz a palavra "abacaxi" na primeira lição. Abacaxi é uma palavra complexa no que diz respeito a sua estrutura grafofonêmica. 'Abacaxi' é uma palavra irregular, em que o grafema ' $x$ ' está em contexto intervocálico e pode ter várias correspondências fonêmicas, podendo corresponder a mais de um som na língua portuguesa. A automatização das irregularidades da língua acontece no terceiro estágio da aprendizagem da leitura pelas crianças, após elas aprenderem a decodificar palavras regulares ('sapo', por exemplo), de correspondência única entre grafema e fonema, e fixarem o princípio alfabético. Porém, para o método global, o que deveria ser feito primeiro, na alfabetização das crianças, era cercá-las de palavras familiares e frequentes, como 'abacaxi', e isso seria suficiente para o desenvolvimento natural da leitura.

A partir da seção abaixo, trazemos evidências de estudos sobre a neurobiologia da leitura e como o cérebro aprende a ler. Estudos científicos que suportam o método fônico e a instrução formal do principio alfabético para a constituição da consciência fonológica da criança. A consciência fonológica e a decodificação podem ter reflexos, inclusive, no processamento de sentenças e na compreensão de textos, pois é um primeiro passo fundamental para uma leitura fluente e automatizada. $O$ cérebro tem de automatizar o processo de decodificação para liberar recursos cognitivos para o acesso ao significado dos itens lexicais e para os processamentos sintáticos e semânticos necessários para a compreensão da leitura. Dessa forma, veremos como as evidências cientificas parecem suportar a utilização do método fônico para a alfabetização.

\section{Evidências científicas da neurobiologia da leitura}

No que tange os processos de leitura, existe um amplo consenso de que dois procedimentos diferentes, também denominados rotas, operam sobre o sistema de leitura e levam o leitor da palavra impressa à fala, mais especificamente, à representação fonêmica, auditiva e/ou articulatória (COLTHEART, 2013). Como veremos abaixo, essas rotas são chamadas de rota fonológica e rota lexical e estão inseridas dentro do chamado Modelo de Dupla Rota.

Segundo o Modelo Cognitivo de Dupla-Rota (ELLIS, 1995), a leitura processa-se em dois niveis: lexical e fonológico. Ambas as rotas de leitura iniciam com o sistema de análise visual, que tem as funções de identificar as letras do alfabeto, a posição de cada letra na palavra, e agrupá-las.

A rota fonológica está baseada no processo de conversão grafema-fonema, que envolve associação de letras ou grupos de letras e fonemas (por meio da aplicação de regras). As representações fonêmicas armazenadas ativam as formas fonológicas das palavras que, por sua vez, levam à ativação das representações semânticas e ortográficas correspondentes. Já a rota lexical depende de representações de palavras familiares armazenadas em um léxico de entrada visual, que é ativado pela apresentação visual de uma palavra. Esse processo é seguido pela obtenção do significado a partir do sistema semântico, e, então, a palavra pode ser articulada. A rota lexical depende de repetição e sistematicidade para que se forme a representação de fácil acesso na leitura. Durante o processo de identificação de palavras, o uso da rota lexical permite acesso mais rápido ao léxico mental por ser um procedimento de acesso direto ao significado a partir da estrutura gráfica. Ao contrário, a rota fonológica é um procedimento sequencial, ao menos no início do desenvolvimento da leitura, e, portanto, mais lento do que o anterior (ELLIS, 1995). Grosso modo, 
a rota fonológica é mais utilizada em leitura de sistemas de escrita transparentes, e a lexical, por sua vez, em sistemas de escrita opacos.

Pode-se resumir o Modelo de Dupla Rota da leitura de palavras da seguinte maneira:

a) rota fonológica ou via indireta: consiste na segmentação fonológica das palavras escritas, isto é, na transformação dos grafemas para fonemas;

b) rota lexical ou via direta: consiste na análise visual das palavras escritas, isto é, em uma interpretação mais imediata e direta da palavra que faz uma transferência simultânea da análise ortográfica para o significado que está armazenado em uma espécie de "dicionário mental", denominado léxico mental ortográfico.

Na figura a seguir, podem-se observar os dois caminhos alternativos que levam ao reconhecimento de palavras na leitura sugeridos por Ellis (1995). Segundo o referido modelo, as palavras conhecidas são pronunciadas por acesso direto (via lexical), enquanto as novas seguem uma via indireta (via fonológica).

Figura 1 - Modelo de Dupla Rota da leitura de palavras

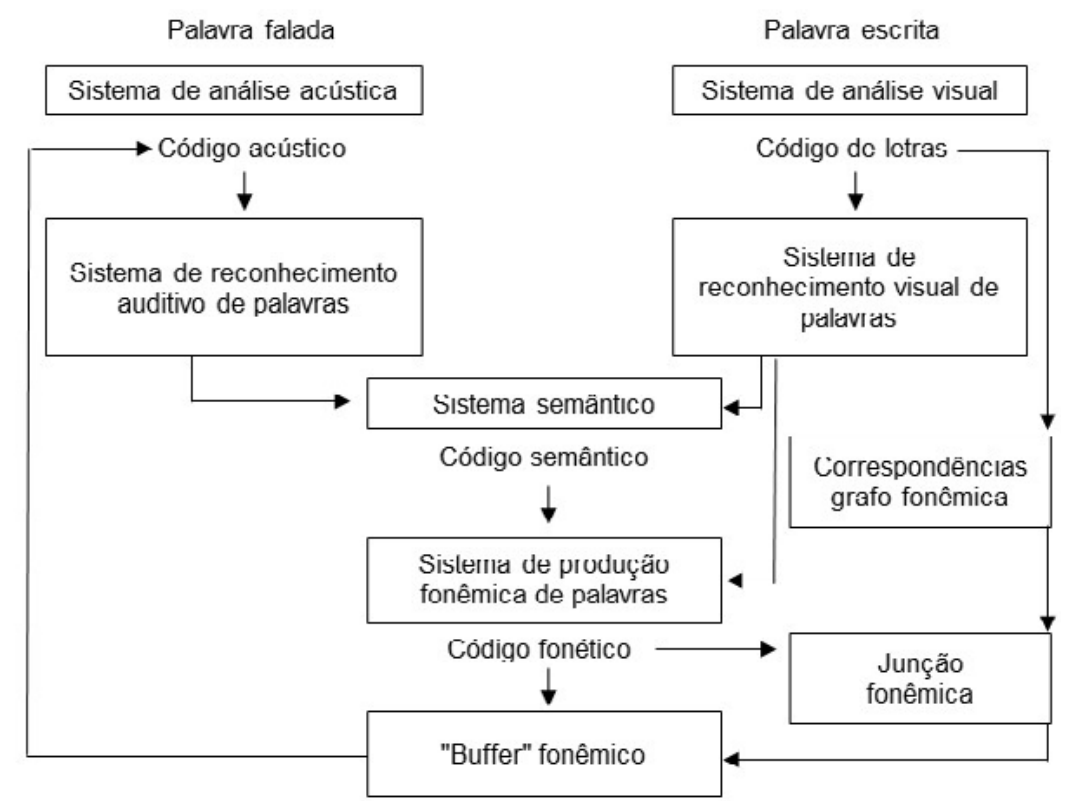

Fonte: Ellis (1995).

A evidência de estudos da neuropsicologia para a existência dessas duas rotas de leitura seria a ocorrência de tipos distintos de dislexia: a dislexia fonológica e a dislexia de superficie (DEHAENE, 2012). Na dislexia fonológica (também chamada de dislexia profunda), a rota fonológica de leitura é afetada, e, por isso, o individuo tem dificuldade em ler palavras raras, mas regulares, neologismos e pseudopalavras. Porém, esses indivíduos conseguem ler palavras frequentes e até mesmo irregulares. Já, na dislexia de superficie, a rota lexical de leitura é afetada, por isso os individuos enfrentam dificuldades para ler palavras irregulares. Contudo, conseguem ler palavras regulares e também pseudopalavras.
Mesmo diante das evidências apresentadas anteriormente, alguns autores contestam o funcionamento dessas duas rotas, se elas trabalhariam de forma simultânea ou isolada e, nesse último caso, em qual ordem. Sobre isso, Coltheart (2013) afirma que os indivíduos começam a calcular pronúncias a partir do zero, ao mesmo tempo que começam a busca lexical. O processo que for concluído primeiro controlaria o produto gerado.

Segundo Capovilla, Dias e Montiel (2007), há uma relação no processamento das duas rotas de leitura e a ativação de dois circuitos principais no cérebro (ambos localizados no hemisfério esquerdo) logo depois que uma palavra é visualizada e a informação é processada pelo córtex visual: 
a) o circuito parietal temporal é ativado pela rota fonológica/via indireta;

b) o circuito occipito-temporal é ativado pela rota lexical/via direta.

Capovilla, Dias e Montiel (2007) postulam que o circuito parietal temporal é ativado assim que a palavra é processada pelo córtex visual e transmitida à região correspondente à junção dos lobos temporal e parietal esquerdo, precisamente para porções mais posteriores do giro temporal superior, angular e supramarginal, incluindo também áreas do giro frontal inferior esquerdo. Há evidências de que essas regiões são ativadas principalmente durante o processo de análise fonológica de uma palavra, ou seja, na segmentação das unidades que a compõem. Outra área também envolvida no processo da leitura silenciosa e em voz alta é a área de Broca. Lá ocorrem os processos de decodificação e recodificação fonológica, e essa área está associada à formação da estrutura sonora, por meio de movimentação dos lábios, da língua e do aparelho vocal.

Segundo Dehaene (2012), essas regiões cerebrais do circuito parietal temporal estariam envolvidas principalmente durante as fases iniciais do aprendizado da leitura. Contudo, elas são estimuladas diante de palavras novas, quando o leitor precisa decodificar grafema por grafema para chegar aos fonemas e verificar se conhece o significado da referida palavra. É importante ressaltar que esse processo acontece independentemente da idade e da capacidade do leitor. o circuito parietal temporal também é ativado em testes com pseudopalavras, que são palavras que não existem na lingua, mas que são possiveis de serem pronunciadas, pois sua construção obedece às regras grafotáticas da língua. Para o diagnóstico dos diferentes tipos de dislexia, e mesmo para uma verificação do grau de desenvolvimento da capacidade de leitura oral, são utilizados testes com pseudopalavras, juntamente com outras palavras existentes na língua.

O circuito occípito-temporal ativa a região da junção dos lobos temporal e occipital esquerdo, mais especificamente os giros lingual e fusiforme e partes do giro temporal médio. Dehaene (2012) afirma que, na região occipito-temporal, ocorre a análise da forma visual da palavra, isto é, uma interpretação mais imediata e direta da palavra. Essa região foi denominada, portanto, área da forma visual das palavras (COHEN et al., 2002; DEHAENE; COHEN, 2011; MCCANDLISS; COHEN; DEHAENE, 2003). Esse circuito é ativado durante a leitura de palavras mais frequentemente usadas em uma determinada língua, ou seja, aquelas com as quais um leitor com maior experiência já teve contato inúmeras vezes, e, por isso, essas palavras passam a ser analisadas de modo mais automático e em um tempo significativamente menor. A figura 2 ilustra as regiões cerebrais envolvidas na leitura. Pesquisas demonstraram que as áreas ativadas são sempre as mesmas, não importando se a escrita é alfabética ou logográfica, nem se a direção da leitura é da esquerda para a direita ou da direita para a esquerda (BOLGER; PERFETTI; SCHNEIDER, 2005; RUECKL et al., 2015).

Figura 2 - Arquitetura cerebral do processamento da palavra escrita

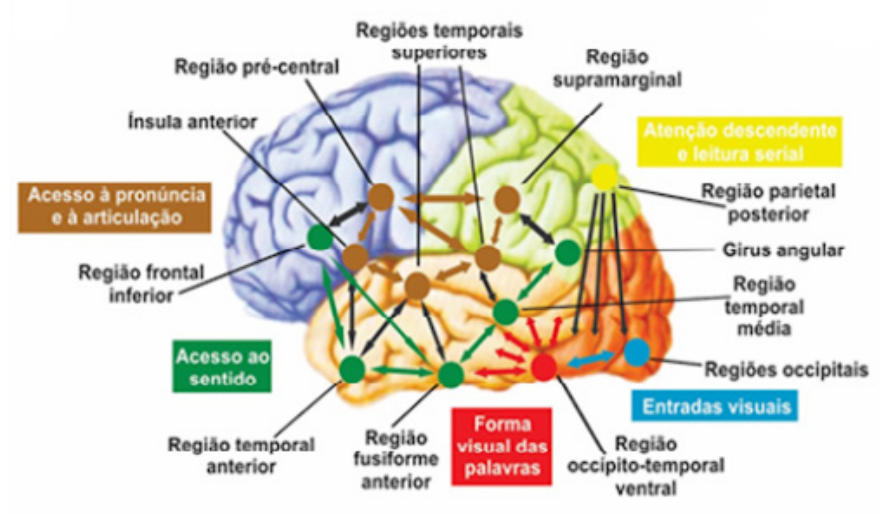

Fonte: Dehane (2012, p. 78) 
Dehaene (2012) mostra a importância da região occipito-temporal esquerda para leitura por meio de estudos com ressonância magnética funcional. Eles demonstraram que todas as pessoas testadas tiveram uma ativação nessa mesma região no decorrer do processo de leitura. A precisão pode variar em função das dobras dos sulcos do córtex cerebral, cuja organização varia de individuo para indivíduo. A área visual da forma das palavras situa-se na região occípito-temporal ventral do hemisfério esquerdo do cérebro. Dehaene (2012) deu a essa área o nome em inglês de Visual Word Form Area (sigla VWFA, traduzida em português por "área da forma visual das palavras - AVFP"), que também ficou conhecida pela denominação Letter Box, "caixa de letras", conforme vimos na seção 2. Essa região do cérebro é caracteristicamente associativa; ou seja, por um lado, conecta-se a áreas que processam as características do estímulo visual e, por outro, a áreas que se ocupam da forma fonológica das palavras, do seu significado e da sua produção oral. Originalmente, a área da forma visual das palavras presta-se ao processamento de faces e outros objetos visuais. É a partir da alfabetização e da automatização de processos no nivel da palavra que esta região se especializa e se adapta, especificamente, para processamento das palavras. Torna-se, dessa forma, uma região cuja ativação na leitura é um marcador de fluência leitora: quanto mais atividade, mais fluência. Da mesma forma, a hipoativação dessa região está associada à baixa fluência leitora e ao risco de dislexia (BUCHWEITZ, 2016; DEHAENE et al., 2015; DEVLIN et al., 2006; SHAYWITZ et al., 2004).

Como apresentado nesta seção, vimos que dois procedimentos diferentes, também denominados rotas, operam sobre o sistema de leitura e levam o leitor da palavra impressa à fala, mais especificamente, à representação fonêmica, auditiva e/ou articulatória, denominado Mode- lo de Dupla Rota (rota fonológica e Lexical). De forma resumida, pode-se dizer que a rota fonológica consiste na segmentação fonológica das palavras escritas, isto é, na transformação dos grafemas para fonemas, já a rota lexical consiste na análise visual das palavras escritas, isto é, em uma interpretação mais imediata e direta da palavra, e que a existência dessas duas rotas de leitura explicaria a ocorrência de tipos distintos de dislexia: a dislexia fonológica e a dislexia de superfície. Por fim, estabeleceu-se que há uma relação no processamento das duas rotas de leitura e a ativação de dois circuitos principais no cérebro (ambos localizados no hemisfério esquerdo). Essas regiões seriam respectivamente a região temporoparietal (rota fonológica) e occípito-temporal (rota lexical).

Na próxima subseção, apresentamos um panfleto com dicas e técnicas baseadas nas evidências dos estudos neurocognitivos apresentados nas seções anteriores.

\subsection{Implicações pedagógicas - panfleto}

Como explicado na introdução do presente artigo, desenvolveriamos um panfleto informativo para professores. O objetivo do panfleto é ilustrar e fazer sugestões práticas sobre alfabetização baseada em evidências científicas e distribuí-lo aos professores do ensino fundamental anos iniciais das redes pública e privada de Porto Alegre.

As informações trazidas no panfleto são uma compilação da parte teórica apresentada nas seções anteriores e de ideias adaptadas do livro "Preparing Children for Learning Success Hands-on activities for librarians, educators, and caregivers" (IRWIN; MOORE, 2015). Essas informações são dicas e técnicas práticas, fundamentadas nas teorias e evidências neurocientíficas sobre como o cérebro aprende a ler e a criança se alfabetiza, organizadas em um panfleto, de forma sucinta, para maior aplicabilidade e rápido entendimento pelos professores (Figura 3). 
Figura 3 - Alfabetização

\section{ALFABETIZAÇÃO BASEADA EM EVIDÊNCIAS CIENTÍFICAS: DICAS E SUGESTÕES}

\section{Para ler e escrever com fluência, o aluno precisa:}

Descobrir o principio alfabético - palavras são formadas por fonemas (sons menores do que a silaba) e que os fonemas, por sua vez, sāo representados por grafemas (letras);

Aprender a decodificar - aprender as relaçōes entre os fonemas e os grafemas que os representam para extrair o som das palavras escritas;

Aprender o princípio ortográfico - as regras que regem a escrita das palavras.

2. O objetivo do professor é que seus alunos entendam que:

\begin{tabular}{|l|l|l|}
\hline $\begin{array}{l}\text { As palavras têm sons: cada } \\
\text { palavra tom um som diforentc. }\end{array}$ & As letras representam os fonemas. & $\begin{array}{l}\text { Para mudar a palavra, precisa } \\
\text { mudar uma ou mais lotras. }\end{array}$ \\
\hline $\begin{array}{l}\text { Quando muda a letra, a palavra } \\
\text { fica diferente, tem outro som. }\end{array}$ & $\begin{array}{l}\text { Para ler, é preciso identificar os } \\
\text { sons que as letras representam. }\end{array}$ & $\begin{array}{l}\text { Analisar e juntar (sintetizar) estes } \\
\text { sons para formar a palavra. }\end{array}$ \\
\hline
\end{tabular}

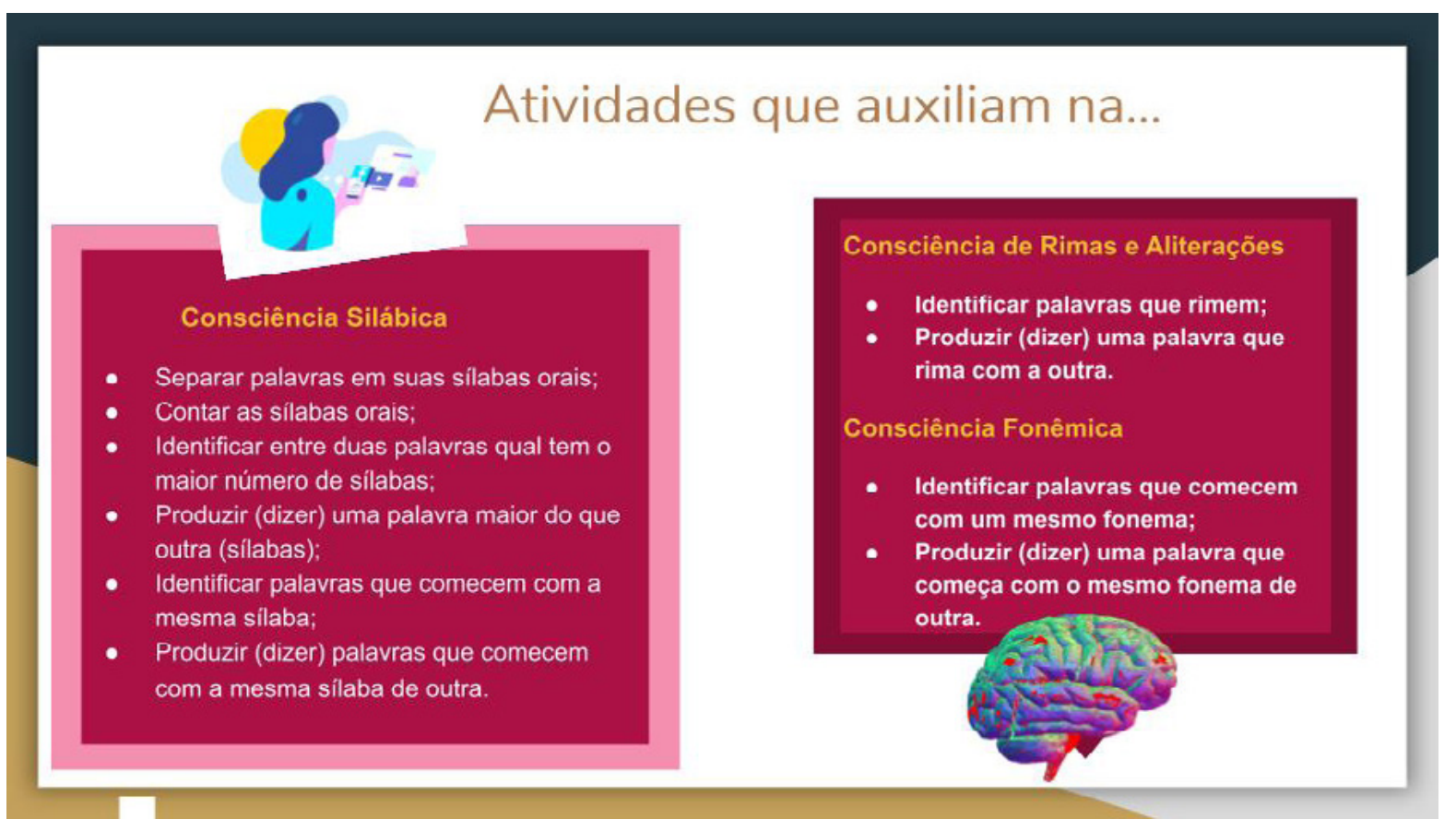

Fonte: Elaborada pelas autoras (2020).

\section{Considerações finais}

Sabe-se que aprender a ler é um processo diferente daquele de aprender a falar. Todas as linguas têm uma modalidade falada, mas nem todas possuem uma versão escrita (LENT, 2010). A fala e a compreensão auditiva desenvolvem-se a partir de uma forte base neurobiológica inata que permite a aquisição da linguagem logo após os primeiros meses de vida. Já a escrita e a leitura são construções culturais que dependem de instrução para que sejam desenvolvidas. No aprendizado dessa invenção que é a escrita, algumas crianças não conseguem desenvolver a leitura de forma fluente e acurada, de maneira 
inesperada (RAMUS, 2004). Os dados no Brasil continuam preocupantes, e a dificuldade começa cedo, com 22\% das crianças, transcorridos três anos de instrução escolar formal, lendo com dificuldade somente palavras soltas.

Com base no exposto, o objetivo principal do presente artigo foi discutir sob o ponto de vista neurocognitivo como o cérebro aprende a ler e, consequentemente, discutir o método mais apropriado para alfabetização. Como vimos, a leitura e a escrita precisam ser ensinadas à criança, que precisa ser propriamente instruida sobre os fonemas e grafemas da sua língua e a correspondência entre eles (letra-som) para decodificar informações escritas e realizar a compreensão. Desse modo, a partir das evidências de estudos neurocognitivos que sublinham a importância do ensino do princípio alfabético e do desenvolvimento da consciência fonológica, elaboramos um panfleto com dicas e técnicas práticas para o ensino da leitura. Algumas crianças apresentam dificuldades para aprender essas habilidades fundamentais para a leitura, como a decodificação (PUGH; MCCARDLE, 2009). A principal caracteristica desse tipo de dificuldade é o baixo rendimento ou desempenho escolar em atividades como leitura, escrita ou cálculos matemáticos (DEHAENE, 2012), o que, como abordamos por meio dos dados, ocorre no Brasil.

A criança precisa aprender que a linguagem tem outras facetas além do significado das palavras utilizado por elas desde cedo na linguagem oral e que a linguagem tem uma forma e uma estrutura, assim ela necessita desenvolver o conhecimento consciente e reflexivo das partes das palavras e como isso se organiza na língua escrita. Como ela aprende tudo isso? Sendo ensinada. Assim, com evidências de como a criança melhor aprende, podemos instrui-la propriamente e facilitar o seu caminho na alfabetização e aprendizado fluente da leitura.

\section{Referências}

ADAMS, M. J. et al. Consciência fonológica em crianças pequenas. Porto Alegre: Artmed, 2012.
AZEVEDO, A. F. Cérebro, leitura e dislexia: um estudo experimental sobre a leitura e as bases neurais da dislexia em monolingues e aprendizes de inglês como l2, com o uso de ressonância magnética funcional. 2016. Tese (Doutorado em Letras) - Pontifícia Universidade Católica do Rio Grande do Sul, Porto Alegre, 2016.

BOLGER, D. J.; PERFETTI, C. A; SCHNEIDER, W. Cross-cultural effect on the brain revisited: universal structures plus writing system variation. Human brain mapping, [S. I.], v. 25, n. 1, p. 92-104, maio 2005.

BUCHWEITZ, A. Language and reading development in the brain today: neuromarkers and the case for prediction. Jornal de Pediatria, [S. I.], v. 92, n. 3, p. S8-S13, 2016.

CAPOVILLA, A. G. S.; DIAS, N. M.; MONTIEL, J. M. Desenvolvimento dos componentes da consciência fonológica no ensino fundamental e correlação com nota escolar. Psico USF, [S. I.], v. 12, n. 1, p. 55-64, 2007.

CHARD, D.; DICKSON, S. Phonological Awareness: Instructional and Assessment Guidelines. Intervention in School and Clinic, [S. I.], v. 34, n. 5, 1999.

CIELO, C. A. A sensibilidade fonológica e o início da aprendizagem da leitura. Letras de Hoje, v. 33, n. 4, p. 99-105, 1998.

COHEN, L. et al. Language-specific tuning of visual cortex? Functional properties of the Visual Word Form Area. Brain: a journal of neurology, [S. I.], v. 125, n. 5, p. 1054-1069, 2002.

COLTHEART, M. Modeling reading: the dual-route approach. In: SNOWLING, M. J.; HULME, C. (ed.). The science of reading: a handbook. Oxford: Blackwell, 2013. p. 6-23.

DEHAENE, S. et al. Illiterate to literate: behavioural and cerebral changes induced by reading acquisition. Nature Reviews Neuroscience, [S. I.], v. 16, n. 4, p. 234-244, 2015.

DEHAENE, S. Os neurônios da leitura: como a ciência explica a nossa capacidade de ler. Porto Alegre: Penso, 2012.

DEHAENE, S.; COHEN, L. The unique role of the visual word form area in reading. Trends in Cognitive Sciences, [S. I.], v. 15, n. 6, p. 254-262, 2011

DEVLIN, J. T. et al. The role of the posterior fusiform gyrus in reading. Journal of cognitive neuroscience, IS. l.], v. 18, n. 6, p. 911-922, jun. 2006.

EHRI, L. C. Learning to Read Words: Theory, Findings, and Issues. Scientific Studies of Reading, [S. I.], v. 9, n. 2, p. 167-188, 2005

EHRI, L. C. Orthographic Mapping in the Acquisition of Sight Word Reading, Spelling Memory, and Vocabulary Learning. Scientific Studies of Reading, [S. I.], v. 18, n. 1, p. 5-21, 2014.

ELLIS, A. W. Leitura, escrita e dislexia: Uma análise cognitiva. 2. ed. Porto Alegre: Artes Médicas, 1995.

FERREIRO, E.; TEBEROSKY, A. Psicogênese da lingua escrita. Porto Alegre: Artes Médicas, 1986. 
FRITH, U. Beneath the surface of developmental dyslexia. In: PATTERSON, K.; MARSHALL, J.; COLTHEART, M. (org.). Surface dyslexia. London: Erlbaum, 1985. p. 301-330.

FLETCHER, J. et al. Transtornos de Aprendizagem da identificação à intervenção. Porto Alegre: Artmed, 2009.

GOSWANI, U. Phonology, reading development and Dyslexia. A cross-linguistic perspective. Annals of Dyslexia, [S. I.], v. 52, p. 141-163, 2002.

GOODMAN, K. Reading: A psycholinguistic guessing game. Journal of the Reading Specialist, [S. I.], v. 6, p. 126-135, 1967.

HILLIS, A. E.; CARAMAZZA, A. The reading Process and Its Disorders. In: MARGOLIN, D. I. (org.). Cognitive Neurophysiology in Clinical Practice. New York: Oxford University Press, 1992. p. 229-261.

INSTITUTO NACIONAL DE ESTUDOS E PESQUISAS EDUCACIONAIS ANISIO TEIXEIRA (INEP). Relatório SAEB/ANA 2016: panorama do Brasil e dos estados. Brasilia: Inep, 2018a.

INSTITUTO NACIONAL DE ESTUDOS E PESQUISAS EDUCACIONAIS ANISIO TEIXEIRA (INEP). Relatório Brasil no PISA 2018. Brasília: INEP, 2018. Disponivel em: http:// download.inep.gov.br/acoes_internacionais/pisa/ documentos/2019/relatorio_PISA_2018_preliminar. pdf. Acesso em: 5 maio 2020.

INSTITUTO BRASILEIRO DE GEOGRAFIA E ESTATISTICA (IBGE). Pesquisa Nacional por Amostra de Domicílio Contínua (PNAD) 2019. Rio de Janeiro: IBGE, 2020.

INSTITUTO PAULO MONTENEGRO. Inaf Brasil 2018. IS. l.: s. n.l, 2018. Disponivel em: http://acaoeducativa.org. br/wp-content/uploads/2018/08/Inaf2018_Relatório-Resultados-Preliminares_v08Ago2018.pdf. Acesso em: 5 maio 2020.

IRWIN, J.; MOORE, D. Preparing Children for Learning Success - Hands-on activities for librarians, educators, and caregivers. Londres: Rowamn \& Littlefield, 2015.

LENT, R. A Linguagem e os Hemisférios Especialistas: A Neurobiologia da Linguagem e das Funções Lateralizadas. In: LENT, R. Cem Milhões de Neurônios? Rio de Janeiro: Atheneu, 2010. p. 681-711.

McCANDLISS, B. D.; COHEN, L.; DEHAENE, S. The visual word form area: Expertise for reading in the fusiform gyrus. In: Trends in Cognitive Sciences, 2003.

MINISTÉRIO DA EDUCAÇÃO (MES). PNA: Política Nacional de Alfabetização. Brasília: Secretaria de Alfabetização, 2019. Disponivel em: http://portal.mec.gov.br/ images/banners/caderno_pna_final.pdf. Acesso em: 9 jun. 2021.

MOOJEN, S. A escrita ortográfica na escola e na clínica: Teoria, avaliação e tratamento. São Paulo: Casa do Psicólogo, 2009.

MORAIS, J. Alfabetizar para a democracia. Porto Alegre: Penso, 2014.

MORAIS, J. Criar Leitores para professores e educadores. Barueri: Manole, 2013.

MORAIS, J. A arte de ler. São Paulo: Editora UNESP, 1996.
MORAIS, J.; KOLINSKY, R. Psicolinguística e leitura. In: MAIA, M. (org.). Psicolinguistica, Psicolinguisticas. São Paulo: Editora Contexto, 2015. p. 129-142.

NASCIMENTO, L.; KNOBEL, K. Habilidades auditivas e consciência fonológica: da teoria à prática. São Paulo: Pró-Fono, 2009.

NATIONAL READING PANEL. Teaching children to read: An evidence-based assessment of the scientific research literature on reading and its implications for reading instruction. NIH Publication, [S. I.], v. 7, n. 00-4769, p. 35, 2000.

NAVAS, A. L:; SANTOS, M. Thereza. Distúrbios de Leitura e Escrita: Teoria e Prática. Barueri: Manole, 2002.

PINHEIRO, Angela. Leitura e Escrita: Uma abordagem cognitiva. São Paulo: Editorial Psy, 2000.

PIAGET, Jean. A Tomada de Consciência. São Paulo: EDUSP; Melhoramentos, 1974.

PUGH, K.; McCARDLE, P. How children learn to read: current issues and new directions in the integration of cognition, neurobiology, and genetics of reading and dyslexia research and practice. New York: Taylor and Francis Group, 2009.

RAMUS, F. The neural basis of reading acquisition. In: GAZZANIGA, M. S. (ed.). The cognitive Neuroscience III. Cambridge MA: MIT Press, 2004. p. 815-824.

REYNOLDS, C. R.; SHAYWITZ, S. Response to Intervention: Ready or not? Or, from wait-to-fail to watch-them-fail. School Psychology Quarterly, [S. I.], v. 24, n. 2. p. 130-145, 2009

RUECKL, J. G. et al. Universal brain signature of proficient reading: Evidence from four contrasting languages. Proceedings of the National Academy of Sciences of United States of America, United States, v. 112, n. 50, p. 15510-15515, 2015.

SCLIAR-CABRAL, L. A desmistificação do método global. Letras de Hoje, Porto Alegre, v. 48, n. 1, p. 6-11, 2013.

SOARES, M. Letramento e alfabetização: as muitas facetas. Revista Brasileira de Educação, [S. I.], n. 25, p. 5-17, 2004

SALLES, J. Habilidades e dificuldades de leitura e escrita em crianças de $2^{a}$ série: abordagem neuropsicológica cognitiva. 2005. Tese (Doutorado em Psicologia) Universidade Federal do Rio Grande do Sul, Porto Alegre, 2005.

SHAYWITZ, S. Entendendo a Dislexia. Um novo e completo programa para todos os niveis de problemas de leitura. Porto Alegre: Artmed, 2006.

SHAYWITZ, S. et al. Development of Left Occipitotemporal System for skilled Reading in Children after a Phonologically Based Intervantion. Biological Psychiatry, [S. I.], v. 55, p. 926-933, 2004.

SNOWLING, M.; HULME, C. (org.). A Ciência da Leitura Porto Alegre: Penso, 2013.

STANOVICH, K.; CUNNINGHAM, A.; CRAMER, B. Assessing phonological awareness in kindergarten children: Issues of task comparability. Journal of Experimental Child Psychology, [S. I.], v. 38, p. 175-190, 1984. 


\section{Mariana Terra Teixeira}

Doutora em Linguística pelo Programa de Pós-Graduação em Letras da Pontificia Universidade Católica do Rio Grande do Sul (PUCRS), em Porto Alegre, RS, Brasil, com bolsa CNPq; estágio de doutorado sanduíche no laboratório Haskins Laboratories, em Yale University, com bolsa CAPES. Mestre em Linguística pela PUCRS. Graduada em Letras Licenciatura Português/Espanhol pela Universidade Federal do Rio Grande do Sul (UFRGS), em Porto Alegre, RS, Brasil, com parte da graduação cursada na Universidade Autónoma de Madrid (UAM). Integrante do grupo de pesquisa Neuroimagem da Cognição Humana, registrado no diretório do CNPq.

\section{Aline Fay de Azevedo \\ Doutora em Linguística pela Pontifícia Universidade Católica do Rio Grande do Sul (PUCRS), em Porto Alegre, RS, Brasil. Coordenadora do curso de graduação em Letras Inglês da PUCRS; professora e coordenadora do LAPREN Inglês/Português e professora adjunta da Escola de Humanidades da PUCRS. Integra o grupo de professores nos cursos de pós-graduação em Gestão da Educação, Docência no Ensino Superior (EAD) e Psicopedagogia da mesma instituição.}

\section{Endereço para correspondência}

Aline Fay de Azevedo

Pontificia Universidade Católica do Rio Grande do Sul

Av. Ipiranga, 6681, Prédio 9, sala 114

Partenon, 97010-082

Porto Alegre, RS, Brasil 